\title{
Caroço de algodão na dieta de cabras saanen no semiárido paraibano
}

\author{
Cottonseed in the diet of Saanen goats in semiarid of Paraiba
}

\author{
ROBERTO, João Vinícius Barbosa ${ }^{2}$; MARQUES, Bênnio Alexandre de Assis²; \\ SOUZA, Bonifácio Benicio de ${ }^{1}$; AZEVEDO, Sérgio Santos de ${ }^{1}$; ASSIS NETO, \\ Dallyson Yehudi Coura de ${ }^{3}$
}

\footnotetext{
${ }^{1}$ Universidade Federal de Campina Grande, Centro de Saúde e Tecnologia Rural, Patos, Paraíba, Brasil.

${ }^{2}$ Universidade Federal de Campina Grande, Programa de Pós-Graduação em Zootecnia, Patos, Paraíba, Brasil.

${ }^{3}$ Universidade Federal da Paraíba, Programa de Pós-Graduação em Zootecnia, Areia, Paraíba, Brasil.

*Endereço para correspondência: viniciusjv@yahoo.com.br
}

\section{RESUMO}

Objetivou-se com o presente trabalho avaliar o efeito da suplementação alimentar com diferentes teores de farelo de caroço de algodão sobre a produção leiteira e o efeito do ambiente sobre as respostas fisiológicas de cabras Saanen no semiárido paraibano. Utilizou-se 16 cabras com peso vivo médio de $55 \mathrm{~kg} \pm 1,41 \mathrm{Kg}$. Para análise da produção leiteira utilizou-se um delineamento em quadrado latino $4 \times 4$ (quatro animais e quatro períodos de 15 dias) com quatro tratamentos, e para os parâmetros ambientais e fisiológicos foi utilizado um delineamento inteiramente casualizado com dois tratamentos (manhã e tarde) e 16 repetições. $\mathrm{Na}$ análise da produção leiteira os tratamentos consistiram na inclusão de quatro teores de caroço de algodão à dieta $(0 ; 3 ; 6$ e $9 \%)$, e na avaliação dos parâmetros ambientais e fisiológicos os tratamentos foram constituídos por dois turnos (manhã e tarde). Avaliaram-se os parâmetros ambientais temperatura do ar, umidade relativa, temperatura do globo negro e fisiológicos: frequência respiratória, temperatura retal e superficial. Nos parâmetros ambientais e também nos fisiológicos observou-se que houve efeito de turnos, com elevação da temperatura ambiente e da frequência respiratória, temperatura retal e superficial. Pela análise de regressão foi verificado que não houve efeito entre os teores de caroço de algodão e a produção média diária de leite, o que permitiu concluir que o caroço de algodão pode ser administrado como complemento na dieta de cabras em lactação e que cabras Saanen, apesar de terem mantido a homeotermia com o aumento da taxa respiratória, se mostraram susceptíveis ao clima semiárido.

Palavras-chave: ambiência, bioclimatologia, estresse calórico, nutrição

\section{SUMMARY}

The present work aimed to evaluate the effects of the feed supplementation with different levels of cotton-seeds on milk production and the effect of environment on the physiological responses of Saanen goats in semiarid of Paraíba. Sixteen goats were used with average weight of $55 \mathrm{~kg} \pm 1,41 \mathrm{~kg}$. For milk production analysis, it was used a latin square design $4 \times 4$ (4 animals and 4 periods of 15 days) with four treatments and for the environmental and physiological parameters it was used a completely randomized design with two treatments (morning and afternoon) and 16 repetitions. In the analysis of milk production the treatments consisted in the inclusion of 4 levels of cotton seeds in the diet $(0 ; 3 ; 6$ and $9 \%)$, in the evaluation of environmental parameters and physiological treatments consisted of two shifts (morning and afternoon). Evaluated the environmental parameters air temperature, relative humidity, black globe temperature and physiological: respiratory rate, rectal temperature and surface temperature. In the environmental and physiological parameters was observed that there was effect of shifts $(\mathrm{P}<0.05)$ with elevation ambient temperature and respiratory rate, rectal temperature and surface temperature. Regression analysis, we determined that there was no correlation between levels of cottonseed and average daily production of milk, so it is possible to conclude that the cotton seeds can be administrate as complement in the diet of goats in lactation and saanen goats, although they maintained homeothermy with increased respiratory rate, proved susceptible to the semiarid climate.

Keywords: ambience, heat stress, bioclimatology, nutrition 


\section{INTRODUÇ̃̃̃O}

A inclusão de fontes de óleo na dieta de ruminantes é uma alternativa para o atendimento às exigências de animais de alta produção leiteira (MAIA et al., 2006), uma vez que possuem maior valor energético em comparação a qualquer outro nutriente, além de representarem a fonte de reserva energética mais importante para os animais (NRC, 2007). $\mathrm{Na}$ tentativa de melhorar os níveis de produtividade leiteira caprina no semiárido e minimizar os custos com concentrados energéticos (milho) e proteicos (soja) é interessante se trabalhar com caroço de algodão, pois de acordo com Zervoudakis et al. (2010) a inclusão de níveis crescentes de farelo de algodão de alta energia reduziu a participação do concentrado nos gastos com alimentação (de 35,49 para $29,18 \%$ na dieta), o que contribuiu para o aumento na margem bruta da atividade produtiva. Além de se tratar de um subproduto da agroindústria, que possui um baixo custo e apresenta disponibilidade em todos os períodos do ano, serve como suplemento nas mais variadas condições de alimentação.

O farelo de algodão é normalmente usado como substituto parcial ou total ao farelo de soja, principalmente em regiões onde se tem o cultivo do algodão e a agroindústria de processamento com a geração do farelo de algodão como coproduto. Isso disponibiliza este produto para mercado local com preço competitivo (ZERVOUDAKIS et al., 2010). É importante destacar ainda que a adição de fontes de lipídios à dieta pode trazer benefícios aos animais ao reduzir o estresse pelo calor, uma vez que há um aumento da concentração energética da dieta com pouca produção de calor de fermentação, o que resulta na diminuição da geração de calor endógeno. (SALLA et al., 2003; SILVA et al., 2006b).
De acordo com Zambom et al. (2006), os maiores níveis de energia na dieta possibilitam, por meio da digestibilidade, um melhor aporte de nutrientes, dentre eles os lipídeos. Assim, poderá ocorrer um aumento na produção leiteira dos animais, já que a produção de leite é um processo metabólico altamente dependente de energia e ao elevar o teor de lipídeos da dieta, ocorrerá um maior aporte da mesma (VARGAS et al., 2001; SILVA et al., 2007).

Diante disso, objetivou-se com esta pesquisa avaliar o efeito da suplementação alimentar com a inclusão de diferentes níveis de farelo de caroço de algodão em substituição ao farelo de soja sobre a produção leiteira, e o efeito do ambiente sobre as respostas fisiológicas de caprinos da raça Saanen no semiárido paraibano.

\section{MATERIAL E MÉTODOS}

O experimento foi realizado no Centro de Saúde e Tecnologia Rural (CSTR), da Universidade Federal de Campina Grande, campus de Patos, semiárido da Paraíba, Brasil. A região é caracterizada por apresentar um clima BSH de acordo com a classificação de Köppen, com índice pluviométrico médio de 590 $640 \mathrm{~mm}$, temperatura anual média máxima de $32,9^{\circ} \mathrm{C}$ e mínima de $20,8^{\circ} \mathrm{C}$ e umidade relativa de $61 \%$ (BRASIL, 1992). Foram utilizadas 16 cabras leiteiras da raça Saanen, com peso vivo médio de $55 \mathrm{~kg} \pm 1,41 \mathrm{~kg}$. Dos mesmos animais foram mensurados tanto os parâmetros fisiológicos como a produção média diária de leite. Antes de iniciar o experimento os animais foram vermifugados, pesados e alojados em um galpão aberto coberto com telhas de cimento amianto, piso de concreto e no sentido leste-oeste. O galpão apresentava 
um comprimento de $11 \mathrm{~m}$ e uma largura de $6 \mathrm{~m}$, com um corredor central de $1,5 \mathrm{~m}$ de largura e pé direito, construído em madeira, de 2,5m. As baias individuais que dividiam o galpão, construídas em madeira, apresentavam dimensões de $1,5 \mathrm{~m} \times 1,0 \mathrm{~m}$ e providas de bebedouros $\mathrm{e}$ comedouros.

Os animais foram mantidos em regime intensivo de criação, alimentados individualmente às $6 \mathrm{hs}$ e $18 \mathrm{hs}$, recebendo concentrado com o capim elefante verde, e ordenhadas manualmente duas vezes ao dia, após o arraçoamento. As dietas dos animais foram ajustadas para atender as necessidades preconizadas pelo Agricultural and Food Research COuncil (AFRC, 1998), para cabras em lactação, mantida a relação volumoso:concentrado de 40:60. O volumoso fornecido foi capim elefante (Pennisetum purpureum) e o concentrado composto por fubá de milho, farelo de soja, ureia, calcário e núcleo mineral. A composição químicobromatológica do volumoso e do concentrado encontram-se na Tabela 1.

Tabela 1. Composição químico-bromatológica dos ingredientes capim-elefante (Pennisetum purpureum), milho, farelo de soja e calcário em percentagem da matéria seca, utilizados nas dietas experimentais

\begin{tabular}{lcccc}
\hline \multirow{2}{*}{ Item $(\% \mathrm{MS})$} & \multicolumn{4}{c}{ Alimento } \\
\cline { 2 - 5 } & Capim elefante & Milho & Farelo de soja & Calcário \\
\hline Matéria seca & 22,0 & 91,81 & 92,87 & 100,00 \\
Proteína bruta & 6,23 & 8,86 & 47,26 & - \\
Extrato etéreo & 2,38 & 5,45 & 4,37 & - \\
Matéria mineral & 9,43 & 10,19 & 7,58 & 99,00 \\
Carboidratos totais & 82,1 & 75,49 & 40,79 & - \\
FDN & 72,3 & 12,82 & 11,27 & - \\
FDA & 46,5 & 2,96 & 28,00 & - \\
Hemicelulose & 31,5 & - & - & - \\
Celulose & 25,3 & - & - & - \\
Lignina & 7,43 & - & - & - \\
Cálcio & 0,28 & 0,78 & 0,93 & 34,00 \\
Fósforo & 0,20 & 0,027 & 0,057 & 0,02 \\
\hline FDN fib
\end{tabular}

FDN= fibra em detergente neutro, FDA= fibra em detergente ácido.

Ao concentrado foram adicionados teores de $0 \% ; 3 \% ; 6 \%$ e $9 \%$ de caroço de algodão em substituição ao de farelo de soja, o que constituiu os quatro tratamentos utilizados na análise de produção leiteira. As dietas foram fornecidas ad libitum, de maneira que houvesse pelo menos $5 \%$ de sobras. A quantidade de volumoso e de ração fornecidos foi calculada diariamente, e as sobras eram pesadas e amostradas diariamente na manhã seguinte. A composição percentual dos ingredientes utilizados nas dietas para cada tratamento encontra-se na Tabela 2 .

$\mathrm{Na}$ fase experimental o leite foi pesado nas duas ordenhas para quantificar a produção média diária no final do experimento. 
Os parâmetros ambientais foram avaliados diariamente, com leituras realizadas às $9 \mathrm{hs}$ e às $15 \mathrm{hs}$, segundo as normas meteorológicas internacionais, com o auxílio de equipamentos como: termômetro de máxima e mínima, termômetro de bulbo seco e úmido, termômetro de globo negro e anemômetro digital. Os equipamentos foram instalados na área experimental e nas mesmas condições ambientais às quais os animais foram expostos. $\mathrm{O}$ objetivo foi o de determinar, através dos dados ambientais, a umidade relativa do ar (UR) e o índice de temperatura e globo negro e umidade (ITGU): ITGU= TGN +0.36 (Tpo) +41.5 , onde TGN corresponde à temperatura do globo negro e Tpo à temperatura do ponto de orvalho (BUFFINGTON et al., 1981).

Tabela 2. Composição percentual dos ingredientes utilizados no concentrado das dietas com diferentes níveis de caroço de algodão em substituição ao farelo de soja

\begin{tabular}{|c|c|c|c|c|}
\hline Ingredientes & $0 \%$ & $3 \%$ & $6 \%$ & $9 \%$ \\
\hline Milho & 83,85 & 82,65 & 80,15 & 77,40 \\
\hline Soja & 13,75 & 11,95 & 11,30 & 11,30 \\
\hline Caroço de algodão & 00,00 & 03,00 & 06,00 & 09,00 \\
\hline Uréia & 00,35 & 00,35 & 00,35 & 00,35 \\
\hline Calcário & 00,30 & 00,30 & 00,45 & 00,20 \\
\hline Núcleo mineral $^{1}$ & 01,75 & 01,75 & 01,75 & 01,75 \\
\hline Total (\%) & 100 & 100 & 100 & 100 \\
\hline
\end{tabular}

Os parâmetros fisiológicos temperatura retal (TR), frequência respiratória (FR) e temperatura superficial (TS) foram aferidos duas vezes por semana, em dois turnos, entre $08 \mathrm{~h} 30 \mathrm{~min}$ e $9 \mathrm{hs}$ e $15 \mathrm{~h} 30 \mathrm{~min}$ e $16 \mathrm{hs}$, e estes turnos foram os tratamentos utilizados na análise dos parâmetros fisiológicos. Para obtenção da temperatura retal (TR) utilizou-se de um termômetro clínico digital com escala de 32 a $43,9^{\circ} \mathrm{C}$, este introduzido no reto do animal e mantido por um período até a emissão de um sinal sonoro, que indicava a estabilização da temperatura. A frequência respiratória (FR) foi obtida através de técnica utilizada e descrita por Souza et al. (2011). A temperatura superficial (TS) foi determinada por meio da média da temperatura da pele de sete pontos distintos do corpo do animal: fronte, pescoço, costado, lombo, coxa, ventre e canela, com o auxílio de um termômetro infravermelho digital sem contato.

Foi utilizado um delineamento em quadrado latino $4 \times 4$ (quatro animais e quatro períodos de 15 dias) com quatro tratamentos. Para a verificação do efeito entre os teores de caroço de algodão e a produção média diária de leite $(\mathrm{kg} / \mathrm{dia})$, foi realizada análise de regressão simples com nível de significância de 5\% (SAMPAIO, 1999), mediante utilização do programa BioEstat versão 5.0.

Para a análise dos dados ambientais e fisiológicos os animais foram distribuídos em um delineamento inteiramente casualizado com dois tratamentos (turnos: manhã e tarde) e 16 repetições. Todos os 
dados obtidos foram analisados através do Programa de Análises Estatísticas e Genéticas SAEG (UFV, 2007) e as médias foram comparadas pelo teste de Tukey, a 5\% de probabilidade.

O período experimental foi de 60 dias, dividido em quatro períodos de 15 dias, dos quais se utilizaram 10 dias de cada período para adaptação à dieta e ao manejo dos animais e os cinco dias restantes foram utilizados para coleta de dados.

\section{RESULTADOS E DISCUSSÃO}

O índice de temperatura de globo negro e umidade (ITGU) é um dos parâmetros ambientais mais utilizados para determinação do conforto ambiental e leva em consideração a radiação térmica, fator ambiental importante para animais criados a pasto. As médias referentes aos parâmetros ambientais indicam que houve efeito de turnos $(\mathrm{P}<$ $0,05)$ em todas as variáveis, com um aumento significativo dessas variáveis no turno da tarde, como demonstra a Tabela 3 .
Os valores observados para o índice de temperatura de globo negro e umidade no turno da tarde na sombra e no sol foram 82,27 e 93,56, respectivamente. Tais valores obtidos se apresentaram elevados e podem ser considerados como indicativos de uma condição ambiental de desconforto térmico, uma vez que os animais também apresentaram um aumento significativo das respostas fisiológicas no turno da tarde, o que indica uma situação de estresse. Ao avaliarem o comportamento fisiológico de caprinos Saanen no semiárido paraibano, Pereira et al. (2011) observaram valores do índice de temperatura de globo negro e umidade no turno da tarde, de 86,4 e 95,1, na sombra e no sol respectivamente, e afirmaram que os valores observados indicaram uma condição térmica de desconforto para os animais. Ao estudar o efeito do ambiente sobre as respostas fisiológicas de caprinos puros Saanen e mestiços $1 / 2$ Saanen $+1 / 2$ Bôer criados em regime semi-intensivo no semiárido paraibano, Souza et al. (2010) registraram valores do índice de temperatura de globo negro e umidade no turno da tarde de 90,2 na sombra e 96,8 no sol, o que concorda com o encontrado na presente pesquisa.

Tabela 3. Médias das variáveis ambientais, temperatura de bulbo seco (TBS), índice de temperatura do globo negro e umidade na sombra (ITUG-SB) e no sol (ITGU-SL), e umidade relativa (UR)

\begin{tabular}{lcccc}
\hline Turno & TBS & ITGU-SB & ITGU-SL & UR\% \\
\hline Manhã & $26,97^{\mathrm{B}}$ & $77,97^{\mathrm{B}}$ & $90,77^{\mathrm{B}}$ & $50,90^{\mathrm{A}}$ \\
Tarde & $32,04^{\mathrm{A}}$ & $82,27^{\mathrm{A}}$ & $93,56^{\mathrm{A}}$ & $42,06^{\mathrm{B}}$ \\
\hline
\end{tabular}

Médias seguidas de letras diferentes na coluna diferem estatisticamente entre si $(\mathrm{P}<0,05)$ pelo teste de tukey a $5 \%$ de probabilidade.

As médias das temperaturas ambientes registradas foram de 26,97 e $32,04^{\circ} \mathrm{C}$ para os turnos manhã e tarde, respectivamente. No turno da manhã, a média obtida está dentro da zona de conforto térmico para caprinos, que segundo Baêta \& Souza (1997), é de 20 a $30^{\circ} \mathrm{C}$. Já no turno da tarde a média de 
$32,04^{\circ} \mathrm{C}$ ultrapassou a temperatura máxima de conforto térmico, que é de $30^{\circ} \mathrm{C}$, e aproximou-se da temperatura crítica de tolerância ao calor que é de $35^{\circ} \mathrm{C}$. Ao estudar o efeito do clima e da dieta sobre os parâmetros fisiológicos e hematológicos de cabras da raça Saanen em sistema de confinamento, no semiárido paraibano, Souza et al. (2011) obtiveram valores semelhantes $(27,12 \mathrm{e}$ $32,06^{\circ} \mathrm{C}$ nos turnos manhã e tarde respectivamente) aos encontrados neste estudo, e também afirmaram que no turno da manhã a média de temperatura ambiente apresentou-se dentro da zona de conforto térmico $\left(20\right.$ a $\left.30^{\circ} \mathrm{C}\right)$ e no turno da tarde a temperatura foi superior a esta zona de conforto térmico.
Com relação à umidade relativa, as médias observadas também demonstram que houve efeito de turno, porém, ao contrário do que foi observado com os outros parâmetros, a maior média foi observada no turno da manhã e não no turno da tarde (URmanhã $=50,90 \%$; URtarde $=42,06 \%$ ), o que concorda com os valores encontrados por Medeiros et al. (2008) ao estudarem as reações fisiológicas de caprinos em diferentes ambientes de sombra e ao sol. Os resultados referentes às variáveis fisiológicas, temperatura retal (TR), frequencia respiratória (FR) e temperatura superficial (TS) estão descritos na Tabela 4.

Tabela 4. Médias das variáveis fisiológicas: temperatura retal $\left({ }^{\circ} \mathrm{C}\right)$, frequência respiratória (mov/min) e temperatura superficial $\left({ }^{\circ} \mathrm{C}\right)$ de cabras saanen suplementadas com diferentes níveis de farelo de caroço de algodão, nos turnos manhã e tarde

\begin{tabular}{lccc}
\hline Turno & TR $\left({ }^{\circ} \mathrm{C}\right)$ & FR $(\operatorname{mov} / \min )$ & TS $\left({ }^{\circ} \mathrm{C}\right)$ \\
\hline Manhã & $38,87^{\mathrm{B}}$ & $44,45^{\mathrm{B}}$ & $29,47^{\mathrm{B}}$ \\
Tarde & $39,10^{\mathrm{A}}$ & $77,62^{\mathrm{A}}$ & $34,30^{\mathrm{A}}$ \\
\hline Média & 38,98 & 61,03 & 31,88 \\
\hline CV(\%) & 0,41 & 21,06 & 3,89
\end{tabular}

Médias seguidas de letras diferentes na coluna diferem entre si $(\mathrm{P}<0,05)$ pelo teste de tukey.

A análise de variância revelou efeito de turno para todas as variáveis, observadas as maiores médias no turno da tarde devido ao estresse térmico mais acentuado nesse período, como demonstra os dados ambientais obtidos (Tabela 2). As médias de temperatura retal observadas nos turnos manhã e tarde respectivamente, foram de $38,87 \mathrm{e}$ $39,10^{\circ} \mathrm{C}$. Em pesquisa para avaliar o efeito do ambiente nas respostas fisiológicas de cabras saanen semiconfinadas e submetidas a diferentes regimes de suplementação, Nunes et al.(2003) observaram valores médios de 38,6 e $39,4^{\circ} \mathrm{C}$ para a temperatura retal nos turnos manhã $\mathrm{e}$ tarde respectivamente. Esses autores afirmaram que os valores da frequência respiratória e da temperatura retal encontrados no período da tarde foram mais elevados provavelmente em função de maiores valores e oscilações das variáveis climáticas, o que concorda com os resultados obtidos na presente pesquisa. Ao estudar o efeito do estresse térmico sobre a produção, composição química do leite e respostas termorreguladoras de cabras da raça alpina, Brasil et al. (2000) também 
encontraram médias de temperatura retal mais elevadas no período da tarde, o que afirma que temperaturas ambientes efetivas mais altas à tarde, associadas à elevação da temperatura corpórea provocada pelo ciclo nictemeral dos animais foram os fatores responsáveis por estes efeitos. Contudo, todas as médias observadas para temperatura retal encontram-se dentro da normalidade de acordo com Baccari Júnior et al. (1996), que considera normal uma variação de $38,5^{\circ} \mathrm{C}$ a $40^{\circ} \mathrm{C}$ para caprinos em repouso.

Com relação à frequencia respiratória, verificou-se também um aumento significativo no turno da tarde em relação ao turno da manhã, tendo a média de $77,62 \mathrm{mov} / \mathrm{min}$, indicado uma maior utilização do sistema termorregulador nesse turno como forma de dissipação de calor para o ambiente, o que mostra o estresse pelo calor.

À medida que a temperatura ambiente aumenta, a eficiência das perdas de calor sensível diminui devido ao menor gradiente de temperatura entre a pele do animal e a do ambiente. Nessa situação, o animal pode até certo ponto manter a temperatura corporal por meio de vasodilatação, que aumenta o fluxo sanguíneo periférico e a temperatura da pele. No entanto, se a temperatura ambiente continuar a subir o animal passa a depender da perda de calor por evaporação através da respiração e ou sudorese (INGRAM \& MOUNT, 1975). Ao avaliar a adaptabilidade de caprinos ao semiárido através de parâmetros fisiológicos e estruturas do tegumento, Silva et al. (2010b) afirmaram que todas as raças estudadas (bôer, savana, anglo nubiana e moxotó) apresentaram médias superiores para frequência respiratória no turno da tarde, o que concorda com os resultados encontrados no presente estudo e observados também por Silva et al. (2006a) e Souza et al. (2008).
As médias de temperatura superficial observadas nos turnos manhã e tarde respectivamente, foram de 29,47 e $34,30^{\circ} \mathrm{C}$. Em experimento desenvolvido na zona litorânea de Salvador-BA, caracterizada por apresentar clima quente e úmido, e cujo objetivo foi determinar o melhor nível de óleo de licuri na dieta de cabritos por meio do comportamento ingestivo e das respostas fisiológicas, Jesus et al. (2010) registraram médias de temperatura superficial de 30 e $30,87^{\circ} \mathrm{C}$ para os turnos manhã e tarde, respectivamente, o que afirma que as condições climáticas durante $o$ período experimental representaram desconforto térmico para os animais. Segundo Medeiros et al. (2001), mesmo na forma indireta, a radiação solar afeta a temperatura superficial, e isto eleva os valores e altera os gradientes térmicos, entre o núcleo central e superficial corporal, a superfície e o meio ambiente. Isso dificulta a dissipação do calor e afeta, também, o processo termorregulatório.

Neste contexto, devido o alto poder de reflexão dos raios solares, os animais que possuem pelagem clara como a raça Saanen, podem apresentar médias de temperatura superficial mais baixas do que animais que possuem pelagem escura, estes em parte mais tolerantes à exposição ao sol (SILVA et al. 2001; ROCHA et al. 2009; SILVA et al. 2011). Entretanto, não devem ser considerados mais adaptados às regiões de clima quente, pois nos animais de pelame branco, a radiação que não é refletida penetra profundamente, atingindo a epiderme, principalmente quando o pelame é pouco denso e os pelos eretos (SILVA et al., 2001).

Pela análise de regressão, foi verificado que não houve correlação entre os níveis de caroço de algodão e a produção média diária de leite (Tabela 5). 
Tabela 5. Média da produção de leite diária em função da adição de níveis crescentes de caroço de algodão adicionados ao concentrado $(0,3,6$ e $9 \%)$ em substituição ao farelo de soja

\begin{tabular}{cc}
\hline Tratamentos & $\begin{array}{c}\text { Produção de leite } \\
\text { (kg/dia) }\end{array}$ \\
\hline $0 \%$ & 1,23 \\
$3 \%$ & 1,24 \\
$6 \%$ & 1,33 \\
$9 \%$ & 1,25 \\
\hline
\end{tabular}

Coeficiente de Correlação $=0,42$; Coefíciente de determinação $\left(R^{2}\right)=0,18 ; P=0,576$.

Contudo, a média da produção de leite alcançada neste experimento, independente dos tratamentos utilizados, é considerada baixa para caprinos da raça Saanen. Possivelmente, esta baixa produção deveu-se tanto aos efeitos do estresse térmico, já que as condições estressantes contribuem para diminuição da ingestão de alimentos e consequentemente para a diminuição da produção, como aos efeitos da ingestão do caroço de algodão. De acordo com Silva et al. (2010a), a maior ingestão de lipídios originários de sementes oleaginosas provoca menores consumos de matéria seca e de proteína bruta pelos animais. Assim, o menor consumo de matéria seca pelo animal afetará negativamente a produção. Ao trabalhar com cabras mestiças moxotó suplementadas com óleo de licuri ou de mamona, Queiroga et al. (2010) observaram que a suplementação com $5 \%$ de óleo de licuri reduziu a produção de leite, já a suplementação com $3 \%$ do mesmo óleo não afetou a produção. Por outro lado, Chizzotti et al.(2005), ao avaliarem o efeito da inclusão da casca de algodão na dieta de novilhos leiteiros em substituição parcial à silagem de capim-elefante, afirmaram que a inclusão da casca de algodão na dieta aumentou linearmente o consumo diário de praticamente todos os nutrientes, tanto em $\mathrm{kg}$ quanto em $\%$ do peso vivo. Já de acordo com Hall \& Akinyode (2000), os dados encontrados na literatura sugerem que o uso de casca de algodão na dieta tem proporcionado consumos superiores, sem, no entanto, aumentar a produtividade animal.

Zambom et al. (2011), ao avaliarem a produção e qualidade do leite de cabras alimentadas com casca do grão de soja em substituição ao milho moído, observaram um aumento da produção de leite total dos animais tratados com $100 \%$ de casca do grão de soja em substituição ao milho moído, e afirma que não houve diferença entre os tratamentos para ingestão de matéria seca e que a casca do grão de soja não altera a ingestão de matéria seca, tanto para animais em crescimento quanto para fêmeas em lactação avançada. Segundo Avila et al. (2001), o uso de fontes lipídicas na ração eleva a eficiência metabólica do animal com resultado positivo sobre a produção de leite em vacas.

Zervoudakis et al. (2010), corroboram a afirmação anterior e concluem que o farelo de algodão de alta energia apresentou potencial para aumentar a rentabilidade da produção de leite quando em substituição ao farelo de soja em dietas de vacas de médio potencial produtivo.

Por outro lado, os resultados obtidos no presente experimento mostram que não ocorreu um aumento da eficiência metabólica dos animais, já que não houve correlação entre os níveis crescentes de caroço de algodão e a produção de leite. A utilização de fontes de óleo na dieta de cabras leiteiras ainda é objeto de muita controvérsia e discussão, pois alguns autores afirmam que tem efeito positivo na produção de 
Rev. Bras. Saúde Prod. Anim., Salvador, v.13, n.1, p.271-282 jan/mar, 2012 http://www.rbspa.ufba.br ISSN 15199940

leite, já outros observam que há uma diminuição da produção.

$\mathrm{O}$ caroço de algodão pode ser administrado como complemento na dieta de cabras em lactação e ser uma alternativa para substituir parte do concentrado com farelo de soja na dieta. O farelo de soja pode ser substituído nos níveis de 0 a 9\% com caroço de algodão, sem alterar a produção de leite de cabras da raça Saanen.

A produção média diária de leite obtida é considerada baixa para a raça Saanen, o que indica sua suscetibilidade ao clima semiárido.

\section{REFERÊNCIAS}

AGRICULTURAL AND FOOD

RESEARCH COUNCIL - AFRC. The nutrition of goat. Report 10. Nutrition

Abstracts \& Reviews (Series B),

Aberdeen, 1998. v67, n. 11, 118.

AVILA, C.D.; DE PETERS, E.J.; PEREZ, H.M.; TAYLOR, S.J.; ZINN, R.A. Influences of saturation ratio of supplemental dietary fat on digestion and milk yield in dairy cows. Journal of Dairy Science, v.83, p.1505-1519, 2001.

BACCARI JÚNIOR, F.;

GONÇALVES, H.C.; MUNIZ, L.M.R. Milk production, serum concentrations of thyroxine and some physiological responses of Saanen-Native goats during thermal stress. Revista

Veterinária Zootécnica, v. 8, n.1, p.914, 1996.

BAÊTA, F.C.; SOUZA, C.F. Ambiência em edificações rurais conforto térmico. Viçosa, UFV, 1997. $246 p$.
BRASIL, Ministério da Agricultura e

Reforma Agrária. Normais

Climatológicas (1961-1990). Brasília:

EMBRAPA/SPI, 1992. 84p.

BRASIL, A.H.L.; WECHESLER, F.S.; BACCARI JÚNIOR, F.;

GONÇALVES, H.C.; BONASSI, I.A.

Efeitos do estresse térmico sobre a produção, composição química do leite e respostas termorreguladoras de cabras da Raça Alpina. Revista Brasileira de Zootecnia, v.29, n.6, p.1632-1641, 2000 .

BUFFINGTON, D.E.; COLLAZOAROCHO, A.; CANTON, G.H.; PITT, D.; THATCHER, W.W.; COLLIER, R.J. Black globe-humidity index (BGHI) as comfort equation for dairy cows. Transactions of the ASAE, v.24, n.3, p.711-714, 1981.

CHIZZOTTI, M.L.; VALADARES

FILHO, S.C.; LEÃO, M.I.; VALADARES, R.F.D.; CHIZZOTTI, F.H.M.; MAGALHÃES, K.A.; MARCONDES, M.I. Casca de algodão em substituição parcial à silagem de capim-Elefante para novilhos. 1 . Consumo, degradabilidade e digestibilidade total e parcial. Revista Brasileira de Zootecnia, v.34, n.6, p.2093-2102, 2005.

HALL, M.B.; AKINYODE, A.

Cottonseed hulls: working with a novel fiber source. In: ANNUAL FLORIDA RUMINANT NUTRITION

SYMPOSIUM, 11., 2000, Gainesville. Proceedings... Gainesville, 2000. p.179-186.

INGRAM, D.L.; MOUNT, L.E. Man and animals in hot environments. New York: Springer-Verlag, 1975. $185 p$. 
Rev. Bras. Saúde Prod. Anim., Salvador, v.13, n.1, p.271-282 jan/mar, 2012 http://www.rbspa.ufba.br ISSN 15199940

JESUS, I.B.; BAGALDO, A.R.; BARBOSA, L.P.; OLIVEIRA, R.L.; GARCEZ NETO, A.F.; SILVA, T.M.; MACOME, F.M.; MARTINS, L.E.P. Comportamento ingestivo e respostas fisiológicas de cabritos $3 / 4$ Boer submetidos a dietas com níveis de óleo de licuri. Revista Brasileira de Saúde e Produção Animal [online], v.11, n.4, p.1176-1186 out/dez, 2010.

MAIA, F.J.; BRANCO, A.F.; MOURO, G.F.; CONEGLIAN, S.M.; SANTOS, G.T.; MINELLA, T.F.; GUIMARÃES, K.C. Inclusão de fontes de óleo na dieta de cabras em lactação: produção, composição e perfil dos ácidos graxos do leite. Revista Brasileira de Zootecnia, v.35, p.1504-1513, 2006.

MEDEIROS, L.F.D.; VIEIRA, D.H.; OLIVEIRA, C.A.; SCHERER, P.O. Frequência respiratória e cardíaca em caprinos de diferentes raças e idades.

Revista Brasileira de Medicina Veterinária, v.23, n.5, p.199-202, 2001.

MEDEIROS, L.F.D.; VIEIRA, D.H.; OLIVEIRA, C.A.; MELLO, M.R.B.; LOPES, P.R.B.; SCHERER, P.O.; FERREIRA, M.C.M. Reações fisiológicas de caprinos das raças AngloNubiana e Saanen mantidos à sombra, ao sol e em ambiente parcialmente sombreado. Boletim de Indústria Animal, v.65, n.1, p.07-17, 2008.

NACIONAL RESEARCH COUNCIL NRC. Nutrient requirements of small ruminants. Washington, D.C.: National Academic Press, 2007. 384p.

NUNES, A.S.; BARBOSA, O.R.; DAMASCENO, J.C. Respostas fisiológicas de cabras leiteiras submetidas ao regime de suplementação com concentrado em dois sistemas de produção. Acta Scientiarum. Animal Sciences, v.25, n.1, p.157-163, 2003.
PEREIRA, G.M.; SOUZA, B.B.; SILVA, A.M.A.; ROBERTO, J.V.B.; SILVA, C.M.B.A.; Avaliação do comportamento fisiológico de caprinos da raça Saanen no semiárido paraibano. Revista Verde de Agroecologia e Desenvolvimento Sustentável, v.6, n.1, p.83-88, 2011.

QUEIROGA, R.C.R.E.; MAIA, M.O.; MEDEIROS, A.N.; COSTA, R.G.; PEREIRA, R.A.G.; BOMFIM, M.A.D. Produção e composição química do leite de cabras mestiças Moxotó sob suplementação com óleo de licuri ou de mamona. Revista Brasileira de

Zootecnia, v.39, n.1, p.204-209, 2010.

ROCHA, R.R.C.; COSTA, A.P.R.; AZEVEDO, D.M.M.R.; NASCIMENTO, H.T.S.; CARDOSO, F.S.; MURATORI, M.C.S.; LOPES, J.B. Adaptabilidade climática de caprinos Saanen e Azul no Meio-Norte do Brasil. Arquivo Brasileiro de Medicina Veterinária e Zootecnia, v.61, n.5, p.1165-1172, 2009.

SALLA, L.E.; FISCHER, V.; FERREIRA, E.X.; MORENO, C.B.; STUMPF JÚNIOR, W.; DUARTE, L.D. Comportamento ingestivo de vacas Jersey alimentadas com dietas contendo diferentes fontes de gordura nos primeiros 100 dias de lactação. Revista Brasileira de Zootecnia, v.32, n.3, p.683-689, 2003.

SAMPAIO, I.B.M. Estatística aplicada à experimentação animal. Belo Horizonte: UFMG/FEPMVZ, 1999. $221 \mathrm{p}$.

SILVA, R.G.; LA SCALA JÚNIOR, N.; POCAY, P.L.B. Transmissão de radiação ultravioleta através do pelame e da epiderme de bovinos. Revista Brasileira de Zootecnia, v.30, n.6, p.1939-1947, 2001. 
Rev. Bras. Saúde Prod. Anim., Salvador, v.13, n.1, p.271-282 jan/mar, 2012 http://www.rbspa.ufba.br ISSN 15199940

SILVA, E.M.N.; SOUZA, B.B.; SILVA, G.A.; CEZAR, M.F.; SOUZA, W.H.; BENÍCIO, T.M.A.; FREITAS, M.M.S. Avaliação da adaptabilidade de caprinos exóticos e nativos no semi-árido paraibano. Ciência e Agrotecnologia,v.30, n.3, p.516-521, 2006a.

SILVA, G.A.; SOUZA, B.B.; ALFARO, C.E.P.; AZEVEDO NETO, J.; AZEVEDO, S.A.; SILVA, E.M.N.; SILVA, R.M.N. Influência da dieta com diferentes níveis de lipídeo e proteína na resposta fisiológica e hematológica de reprodutores caprinos sob estresse térmico. Ciência e Agrotecnologia, v.30, n.1, p.154-161, 2006 b.

SILVA, M.M.C.; RODRIGUES, R.H.; BRANCO, R.H.; SARMENTO, C.A.F.; SARMENTO, J.L.R.; QUEIROZ, A.C.; SILVA, S.P. Suplementação de lipídios em dietas para cabras em lactação: consumo e eficiência de utilização de nutrientes.

Revista Brasileira de Zootecnia, v.36, n.1, p.257-267, 2007.

SILVA, G.L.S.; SILVA, A.M.A.; NÓBREGA, G.H.; AZEVEDO, S.A.; PEREIRA FILHO, J.M.; MENDES,

R.S. Efeito da inclusão de fontes lipídicas na dieta de cabras em lactação sobre os parâmetros sanguíneos. Ciência e

Agrotecnologia, v.34, n.1, p.233-239, 2010a.

SILVA, E.M.N.; SOUZA, B.B.; SOUSA, O.B.; SILVA, G.A.; FREITAS, M.M.S. Avaliação da adaptabilidade de caprinos ao semiárido através de parâmetros fisiológicos e estruturas do tegumento. Revista Caatinga, v.23, n.2, p.142148, $2010 \mathrm{~b}$.
SILVA, C.M.B.A.; SOUZA, B.B.; BRANDÃO, P.A.; MARINHO, P.V.T.; BENÍCIO, T.M.A. Efeito das condições climáticas do semiárido sobre o comportamento Fisiológico de caprinos mestiços fl Saanen x boer. Revista Caatinga, v.24, n.4, p.195-199, 2011.

SOUZA, B.B.; SOUZA, E.D.; CEZAR, M.F.; SOUZA, W.H.; SANTOS, J.R.S.; BENÍCIO, T.M.A. Temperatura superficial e índice de tolerância ao calor de caprinos de diferentes grupos raciais no semi-árido nordestino. Ciência e Agrotecnologia, v.32, n.1, p.275-280, 2008.

SOUZA, B.B.; LOPES, J.J.; ROBERTO, J.V.B.; SILVA, A.M.A.; SILVA, E.M.N.; SILVA, G.S.; Efeito do ambiente sobre as respostas fisiológicas de caprinos Saanen e mestiços $1 / 2$ saanen $+1 / 2$ boer no semiárido paraibano. Agropecuária científica no semiárido, v.6, n.2, p.47$51,2010$.

SOUZA, B.B.; ASSIS, D.Y.C.; SILVA NETO, F.L.; ROBERTO, J.V.B.; MARQUES, B.A.A. Efeito do clima e da dieta sobre os parâmetros fisiológicos e hematológicos de cabras da raça saanen em confinamento no sertão paraibano.

Revista verde de agroecologia e desenvolvimento sustentável, v.6, n.1, p. $77-82,2011$.

UNIVERSIDADE FEDERAL DE VIÇOSA - UFV. SAEG 9.1: Sistema de Análises Estatística. Viçosa, MG: Fundação Arthur Bernardes, 2007.

VARGAS, L.H.; LANA, R.P.; MÂNCIO, A.B.; CAMPOS, J.M.S.; JHAM, G.N.; FREITAS, A.W.P.; OLIVEIRA, M.V.M. Influência de rumensin, óleo de soja e níveis de concentrado sobre o consumo e os parâmetros fermentativos ruminais em bovinos. Revista Brasileira de Zootecnia, v.30, p.1650-1658, 2001 
Rev. Bras. Saúde Prod. Anim., Salvador, v.13, n.1, p.271-282 jan/mar, 2012 http://www.rbspa.ufba.br ISSN 15199940

ZAMBOM, M.A.; ALCALDE, C.R.; MACEDO, F.A.F.; GARCIA, J.; MORAES, G.V.; SAKUNO, M.L.D.; BORGH, E.L. Ingestão, digestibilidade das rações e parâmetros sangüíneos em cabras Saanen durante o pré-parto recebendo rações com diferentes níveis de energia. Revista Brasileira de Zootecnia, v.35, n.4, p.1866-1871, 2006. Supl.

ZAMBOM, M.A.; ALCALDE, C.R.; SILVA, K.T.; MACEDO, F.A.F.; RAMOS, C.E.C.O.; GARCIA, J.; HASHIMOTO, J.H.; LIMA, L.S.

Produção e qualidade do leite de cabras alimentadas com casca do grão de soja em substituição ao milho moído.

\section{Revista Brasileira de Saúde e}

Produção Animal [online], v.12, n.1, p.126-139, 2011.
ZERVOUDAKIS, J.T.; LEONEL,F.P.; CABRAL,L.S.; HATAMOTOZERVOUDAKIS,L.K.; ALVES,A.F.; COSENTINO,P.N.; PAULA,N.F.; CARVALHO, D.M.G. Substituição do farelo de soja por farelo de algodão alta energia em dietas para vacas leiteiras: composição do leite e custo de produção. Revista Brasileira de Saúde e Produção Animal [online], v.11, n.1, p 150-159, 2010.

Data de recebimento: 29/06/2011

Data de aprovação: 11/11/2011 